\title{
The MoSGrid - e-science gateway: molecular simulations in a distributed computing environment
}

\author{
Lars Packschies ${ }^{1 *}$, Georg Birkenheuer², Dirk Blunk1', Sebastian Breuers', André Brinkmann², Ines dos Santos Vieira ${ }^{3}$, \\ Gregor Fels ${ }^{2}$, Sandra Gesing ${ }^{6}$, Richard Grunzke ${ }^{5}$, Sonja Herres-Pawlis ${ }^{4}$, Oliver Kohlbacher ${ }^{6}$, Jens Krüger ${ }^{6}$, \\ Martin Kruse ${ }^{1}$, Ulrich Lang ${ }^{1}$, Ralph Müller-Pfefferkorn ${ }^{5}$, Patrick Schäfer ${ }^{7}$, Tobias Schlemmer ${ }^{5}$, Thomas Steinke ${ }^{7}$, \\ Klaus-Dieter Warzecha', Andreas Zink ${ }^{6}$
}

From 8th German Conference on Chemoinformatics: 26 CIC-Workshop

Goslar, Germany. 11-13 November 2012

Modern tools for computational chemistry allow the calculation of a wide range of properties of all sorts of molecules applying various levels of theory. But to perform convincing and significant calculations with these tools not only requires insight into the scientific theory itself, but also knowledge and experience on how to operate the simulation tools.

In addition to the general challenge of gaining access to a powerful computing environment, very often a high level of technical competence is necessary to set up and run calculations efficiently. These prerequisites often hamper scientists to routinely use computational tools to support or confirm their perceptions.

To overcome some of these problems, the MoSGrid consortium develops an open source e-science portal for grid based environments with respect to computational chemistry. At present residing in the German Grid Initiative (D-Grid), MoSGrid enables users to set up, run and evaluate calculations using tools from the domains of Quantum Chemistry, Molecular Dynamics and Docking [1].

This talk underlines the basic motivation, layout, development, properties and available tools of MoSGrid as well as the procedure of gaining access to the grid environment.

\begin{abstract}
Author details
'Universität zu Köln, 50923 Köln, Germany. ${ }^{2}$ Universität Paderborn, 33098 Paderborn, Germany. ${ }^{3}$ Technische Universität Dortmund, 44221 Dortmund, Germany. ${ }^{4}$ Ludwig-Maximilians-Universität München, 81377 München, Germany. ${ }^{5}$ Technische Universität Dresden, 01069 Dresden, Germany. ${ }^{6}$ Eberhard Karls Universität Tübingen, 72074 Tübingen, Germany. ${ }^{7}$ Zuse Institut Berlin, 14195 Berlin, Germany.
\end{abstract}

Published: 22 March 2013

Reference

1. Gesing S, Kacsuk P, Kozlovszky M, Birkenheuer G, Blunk D, Breuers S, Brinkmann A, Fels G, Grunzke R, Herres-Pawlis S, Krüger J, Packschies L, Müller-Pfefferkorn R, Schäfer P, Steinke T, Szikszay Fabri A, Warzecha KD, Wewior M, Kohlbacher O: A Science Gateway for Molecular Simulations. EGI User Forum 2011, Book of Abstracts, pp. 94, ISBN 97890816927.

doi:10.1186/1758-2946-5-S1-O3

Cite this article as: Packschies et al:: The MoSGrid - e-science gateway: molecular simulations in a distributed computing environment. Journal of Cheminformatics 2013 5(Suppl 1):O3.

\section{Publish with ChemistryCentral and every} scientist can read your work free of charge

"Open access provides opportunities to our colleagues in other parts of the globe, by allowing anyone to view the content free of charge."

W. Jeffery Hurst, The Hershey Company.

- available free of charge to the entire scientific community

- peer reviewed and published immediately upon acceptance

- cited in PubMed and archived on PubMed Central

- yours - you keep the copyright

Submit your manuscript here:

http://www.chemistrycentral.com/manuscript/

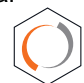
ChemistryCentral 